\title{
CRÍTICA AO HISTORICISMO E JEZTZEIT: BREVE LEITURA DA TESE XVIII E DOS APÊNDICES DE SOBRE O CONCEITO DE HISTÓRIA
}

\author{
Barbara Smolniakof
}

\begin{abstract}
RESUMO
Este breve artigo pretende apresentar uma leitura pormenorizada da tese XVIII e dos apêndices de Sobre o conceito de história de Walter Benjamin, onde ele explica porque o historicismo não é o melhor modo de abordar a história e define o principal conceito do seu livro, isto é, o jeztzeit.
\end{abstract}

Palavras-chave: Benjamin. História. Jeztzeit.

\section{CRITICISM TO HISTORICISM AND JEZTZEIT: BRIEF READING OF THE THESIS XVIII AND THE APPENDICES OF ON THE CONCEPT OF HISTORY}

\begin{abstract}
This brief article intends to present a detailed reading of the thesis XVIII and the appendices of Walter Benjamin's On the concept of History, where he explains why historicism is not the best way to approach history and defines the main concept of his book, this is, the Jeztzeit.
\end{abstract}

Key-words: Benjamin. History. Jeztzeit.

\section{Introdução}

A partir de uma crítica à experiência moderna de tempo cujo fio condutor é a noção de progresso e é denominada como historicismo, Walter Benjamin elabora nas teses "Sobre o conceito de história" uma nova concepção de tempo. Para isso, ele leva em consideração a história de dois modos: (i) como o conjunto de acontecimentos passados e (ii) como as narrativas sobre esses acontecimentos. Este breve texto visa dois objetivos gerais. Primeiro, expor essa crítica a partir do apêndice A das teses "Sobre o conceito de história" apresentando as características do historicismo. Segundo, apresentar o que Benjamin propõe pensar como jeztzeit ou tempo-de-agora a partir da tese XVIII 
e do apêndice B do mesmo texto; tal conceito elementar parece ter como pressupostos o materialismo histórico e o messianismo.

Apesar de nos determos mais especificamente à última tese e aos apêndices de Sobre o Conceito de História, vez ou outra faremos referência a outras teses do mesmo texto, visto que elas podem ajudar a compreender melhor certas ideias. A escolha dos apêndices e da última tese do texto como objeto central desta exposição se deve ao fato de que parece ser neles que Benjamin define de maneira mais específica o que é o Jeztzeit. De fato, Benjamin fala dessa noção recorrentemente em praticamente todo o texto, mas, curiosamente, parece ser apenas no final do texto que sua definição é dada a partir da apresentação de suas notas mais características.

\section{Contra o historicismo}

Parece pertinente começar pelo apêndice $A$, presente no fim das teses sobre o conceito de história, porque é nele que Benjamin fala sobre o historicismo e o caracteriza como uma corrente que tende a identificar meros fatos como históricos a partir de uma causalidade entre eles. Mais do que isso, o historicismo se caracteriza como um modo de ver o tempo histórico como uma série infinita de acontecimentos semelhantes e causalmente relacionados em direção a uma finalidade (télos), que se deduz como uma história universal capaz de apreender através da investigação histórica a verdade objetiva dos acontecimentos. Benjamin caracteriza essa concepção de história como um espaço "vazio e homogêneo": vazio por ser uma linha infinita sem conteúdo que tem como certo/relevante apenas seu fim e homogêneo por ser preenchido de modo cumulativo por uma série de eventos semelhantes e causalmente relacionados entre si, tal como ele diz já na tese XVII: "Seu procedimento é aditivo. Ela utiliza a massa dos fatos, para com eles preencher o tempo homogêneo e vazio" (BENJAMIN, 2005, Tese XVII).

O historiador que faz parte do que Benjamin chama historicismo olha a história sob o ponto de vista unicamente científico e objetivo, o que faz com ele permaneça acrítico frente aos fatos passados e frente ao seu próprio presente. Nas palavras de Gagnebin em Cacos da história, o "historiador burguês não 
questiona nem sua posição, nem a maneira pela qual a história nos foi contada e transmitida, e ainda menos, a maneira pela qual ela se realizou" (GAGNEBIN, 1993, 56). Nesse sentido, a história não é apenas uma história entre outras, mas "o relato incontestável e edificante das múltiplas manifestações da vida humana" (Idem, ibidem). Assim, ao não se pôr de modo crítico frente aos eventos históricos e propor uma escrita e transmissão objetivas desses mesmos eventos, 0 historiador do historicismo acaba por disfarçar a luta de classes que é, para Benjamin, o pano de fundo da história. Ao ignorá-la o historicismo se conforma com a história dos vencedores e a reproduz (Cf. BENJAMIN, 2005, Tese VII, 70).

A luta de classes é o elemento material da formulação do conceito benjaminiano da história (Cf. PEREIRA, 2008), seu método materialista da história encontra antecedentes na obra História e consciência de classes de Lúkacs (Cf. LÖWY, 2005, Introdução) e tem como função resgatar o sentido político e social da experiência de tempo, em contraposição a uma experiência unilateral e vazia que se pretende objetiva como a do historicismo. Além disso, a história que Benjamin propõe que se conte é aquela dos eventos e pessoas esquecidos pelo historicismo (Cf. FREITAS, 110). E ele vê no materialismo histórico o método mais adequado para tal, pois é o materialismo que se coloca contra o historicismo e a teoria social democrata - estas entendem a evolução histórica como um efeito necessário do progresso técnico e econômico, ao qual resta apenas esperar, como ele mesmo fala na tese XIII sobre o conformismo.

No apêndice A das teses Benjamin diz:

\begin{abstract}
O historicismo contenta-se em estabelecer um nexo causal entre os diversos momentos da história. Mas nenhum fato, por ser causa, já é, só por isso, um fato histórico. Ele se tornou tal postumamente, graças a eventos que dele podem estar separados por milhares de anos. $O$ historiador que parte disso cessa de passar a sequência dos acontecimentos pelos seus dedos como as contas de um rosário. Ele apreende a constelação em que sua própria época entrou com uma determinada época anterior. Ele fundamenta, assim, um conceito de presente como tempo-de-agora, no qual estão incrustados estilhaços do tempo messiânico. (BENJAMIN, 2005, apêndice A, 140)
\end{abstract}

Neste trecho Benjamin critica a relação causa-efeito que o historicismo estabelece como algo intrínseco aos fatos. Segundo ele, um fato não é histórico apenas por ser causa, por isso o historiador deve adotar outro método de análise da história que não o causal. A relação que liga fatos passados ao contexto atual no qual o historiador se encontra é percebida a partir do que Benjamin chama 
"constelação". Ao que parece, o elemento da constelação, como o que caracteriza o fato passado como histórico reconhecido a partir do presente, parece ser algo como um retorno - é nesse retorno ao passado, a partir do presente no qual o historiador se encontra, que ele percebe a importância de tal evento passado para a história. E esse retorno é feito enquanto rememoração, elemento fundamental para a caracterização da concepção histórica de Benjamin como Jeztzeit.

Ao não perceber a história como fragmentada em passado-presentefuturo e o passado como algo que ficou para trás, mas como um evento percebido no presente, trazido à tona no presente, o historiador funda um conceito novo de presente como "tempo-de-agora", que interrompe a linha reta da história progressista, justamente porque não vê um evento passado meramente como um evento esquecido que ficou no passado, mas o vê em relação ao presente. E é neste "agora" onde se encontram o que ele chama "estilhaços do tempo messiânico", que são como pequenos momentos em que há a possibilidade de rememorar algo do passado a partir de uma nova percepção do tempo (que possibilita uma nova narrativa), diferente do tempo linear e causal, o qual é análogo a "contas de um rosário" (Cf. OTTE, 1994, 39).

\section{0 jeztzeit como tempo benjaminiano}

Dada a caracterização da crítica de Benjamin ao historicismo, passemos agora à definição do tempo-de-agora. Ela já aparece na tese XIV como o que preenche a história: "A história é objeto de uma construção, cujo lugar não é formado pelo tempo homogêneo e vazio, mas por aquele saturado pelo tempode-agora (Jeztzeit)". (BENJAMIN, 2005, Tese XIV, 119), mas parece ser o tema central da tese XVIII, onde ele diz:

\footnotetext{
"Os míseros cinquenta mil anos do homo sapiens", diz um biólogo recente, "representam, em relação à história da vida orgânica sobre a terra, algo como dois segundos ao fim de um dia de vinte e quatro horas. Inscrita nessa escala, a história inteira da humanidade civilizada perfaz um quinto do último segundo da última hora". O tempo-de-agora que, enquanto modelo do tempo messiânico, resume a história de toda a humanidade numa prodigiosa abreviação, coincide, exatamente, com a figura que a história da humanidade ocupa no universo. (BENJAMIN, 2005, Tese XVIII, 138)
}

Para ilustrar o tempo-de-agora ou Jeztzeit Benjamin elabora uma analogia 
de três partes citando um biólogo, que, apesar de não ser identificado, sugere que pensemos num relógio. O seu curso completo de 24 horas, ou seja, a totalidade do tempo desde seu momento inicial até o presente, representa a história da vida orgânica como um todo. Os dois últimos segundos da última hora representam a história do homo sapiens e o último quinto do último segundo, isto é, uma parcela mínima de todo o tempo circunscrito pelo relógio, representa toda a história da humanidade civilizada. O que Benjamin chama de jeztzeit é equivalente a toda a história de toda a humanidade, que, se comparada à história ou tempo atribuído ao surgimento da vida como um todo, é uma parcela mínima.

Aqui parecem haver dois tempos: (i) aquele atribuído ao surgimento da vida, que é objeto de estudo da biologia, e que é muito maior que aquele (ii) tempo atribuído ao surgimento do homem, que é objeto da história. Ao comparar toda a história da humanidade mencionada pelo biólogo ao seu conceito de Jeztzeit, parece que sua intenção é salientar a brevidade desse tempo, que, por dizer respeito à história de toda a humanidade, abrange tanto a história que já foi contada, narrada, quanto as histórias não- contadas ou esquecidas.

O Jeztzeit é uma abreviação de toda a história porque é um conjunto que envolve tanto o presente e o passado histórico, isto é, registrado, quanto o passado esquecido, mas que é rememorado no próprio presente pelo historiador materialista. Nesse sentido, o termo "agora" que Benjamin utiliza para denominar sua concepção de história não parece ser usado no sentido ordinário de momento atual ou recente apenas, ele o ressignifica para caracterizar o tempo como uma unidade (da presença) dos momentos passados no presente (Cf. OTTE, 1994,84). E essa unidade é feita como interrupção do tempo linear através da rememoração da história que não foi contada ou foi simplesmente esquecida.

A rememoração é um elemento chave que caracteriza o tempo benjaminiano, pois é ela que permite que o tempo-de-agora quebre o tempo linear que Benjamin critica na medida em que resgata do esquecimento aquilo que o tempo linear não conta. Mencionamos brevemente que o elemento material da formulação benjaminiana de tempo é a luta de classes, segundo ele a história é contada do ponto de vista de quem sempre vence e, por consequência, quem é vencido ou oprimido é sempre ignorado por quem escreve a história. Aliado a esse materialismo, Benjamin também usa de elementos residente em Guarapuava - PR. E-mail: barbarasmolniakof@gmail.com 
teológicos que fundamentam o tempo-de-agora como reformulação da história, e a rememoração é um desses elementos, junto com a redenção como o que resultaria da rememoração (Cf. PEREIRA, 2008).

É no apêndice $B$ das teses que Benjamin dá atenção a esses elementos de origem messiânica, onde ele escreve:

\begin{abstract}
O tempo ao qual os adivinhos perguntavam o que ele ocultava em seu seio, não era, certamente, experimentado nem como homogêneo, nem como vazio. Quem mantém isso diante dos olhos talvez chegue a um conceito de como o tempo passado foi experienciado na rememoração: ou seja, precisamente assim. Como se sabe, era vedado aos judeus perscrutar o futuro. A Torá e a oração, em contrapartida, os iniciavam na rememoração. Essa lhes desencantava o futuro, ao qual sucumbiram os que buscavam informações junto aos adivinhos. Mas nem por isso tornou-se para os judeus um tempo homogêneo e vazio. Pois nele cada segundo era a porta estreita pela qual podia entrar 0 Messias (BENJAMIN, 2005, apêndice B, 142).
\end{abstract}

Parece haver dois momentos nesse trecho. Benjamin começa por apresentar o modo como os adivinhos se comportavam em relação ao tempo. Se eles quisessem saber o que o tempo escondia, ou seja, o que estava por vir, certamente eles não podiam vê-lo como homogêneo e vazio (atributos que Benjamin dá à noção linear de tempo). Aquele que chega a um conceito de tempo que experiencia o passado a partir do elemento da rememoração vê o tempo do mesmo modo que os adivinhos, ou seja, não como vazio e homogêneo, mas de uma maneira diferente.

Aqui Benjamin parece estar fazendo menção a ele mesmo, uma vez que ele defende uma concepção diferente de história e, por conseguinte, tem uma visão diferente do próprio passado; ou, no limite se refere aos historiadores que se servem de seu método materialista. A questão é, e esse parece ser o segundo momento do trecho, que a rememoração surge como elemento importante para sua noção de história, elemento este descrito a partir da sua valorização pela religião judaica: pois Benjamin menciona a Torá, que traz a rememoração como imperativo (Zahor!) ${ }^{1}$ através do qual o presente mantém vínculo com o passado e é iluminado por ele.

A rememoração é importante também porque com ela o historiador não se prende a um futuro inevitável, típico de uma história progressista. Na medida em que o jeztzeit traz para o presente o passado esquecido, a rememoração

${ }^{1}$ Cf. LÖWY, 2005, p.142. Comentário de Michael Löwy ao apêndice B das teses sobre o conceito de história. 
enquanto aquilo que o permite é também o elemento redentor da história, pois é rememorando o que foi deixado de lado pelo historicismo e todas as ideologias progressistas, que se redime a própria história. Enquanto termo de caráter teológico, a redenção é possibilitada pelo Messias. Enquanto termo aliado à história e usado em sentido profano por Benjamin, a redenção tem caráter político e linguístico na medida em que ao rememorar a história e restaurar os cacos deixados pelo historicismo se faz justiça àqueles que foram esquecidos (Cf. CANTINHO, 2015, 50; OTTE e VOLPE, 2000, 44).

Ainda de acordo com a citação, o tempo que enfatiza a rememoração, isto é, que se volta para o passado e o traz à tona ao invés de se preocupar com o futuro, não é visto também pelos judeus como homogêneo e vazio. Ele não é homogêneo porque relembra inúmeros fatos diferentes daqueles que foram cristalizados pelo historicismo, nesse sentido, ele não é um tempo fechado. E também não é vazio porque não se trata de uma linha infinita na qual o que importa é apenas a finalidade, mas é uma constelação, ou seja, um conjunto que une todos os elementos do passado ao presente, nesse sentido, ele é pleno.

Além disso, a rememoração da tradição judaica é o que proporciona a vinda do Messias, como Benjamin fala no final do trecho: "pois nele [no tempo da rememoração] cada segundo era a porta estreita pela qual podia entrar o Messias". A figura teológica do Messias é transportada para a atividade do historiador do materialismo histórico, que tem a chance de redimir a humanidade enquanto rememora e narra histórias e não a história. Segundo a interpretação de Gagnebin, o historiador como quem representa o Messias não exatamente redimiria a humanidade por rememorar, ou seja, a redenção não estaria presente na própria rememoração, mas no modo como essa rememoração interrompe a história, dá precisamente um fim à história linear. Nesse sentido, não é que a rememoração conserve ou cultue o passado, mas ela destrói a história linear que separa o passado do presente e se concentra no futuro.

\section{CONCLUSÃO}

Assim, as características do tempo-de-agora formulado por Benjamin podem ser elencadas da seguinte forma: ele é heterogêneo, por resgatar a diferença que foi esquecida; é também pleno, por unificar passado e presente, a 
partir do qual o futuro é dado como esperança de redenção e não como uma coisa concreta e inevitavelmente garantida. Além disso, na medida em que esta história traz aquilo que o historicismo deixou para trás em nome de uma verdade que se pretende necessária, ela atua no campo das possibilidades, pois diz respeito à história daquilo que foi e também do que não foi, mas poderia ter sido.

Em contraposição ao método aditivo do historicismo que move a massa dos fatos apenas para preencher o tempo vazio, a história proposta por Benjamin é também qualitativa, no sentido de que dá o devido valor a cada evento passado a partir do presente no qual o historiador não apenas o rememora ao invés de apenas descrevê-lo, mas também usa do passado para pensar e criticar o próprio presente (Cf. LÖWY, 2005, Introdução). Por fim, a história como jeztzeit é redentora na medida em que resgata e traz à tona o que fora esquecido pelo historicismo: as histórias dos vencidos.

\section{REFERÊNCIAS}

BENJAMIN, W. Sobre o conceito de história. In_ : LÖWY, M. Walter Benjamin: Aviso de Incêndio: uma leitura das "Teses sobre o conceito de história". São Paulo: Boitempo, 2005.

CALLADO, T. C. A metafísica benjaminiana e o agora (jeztzeit). In : Cadernos Walter Benjamin. Vol. 2, jan. /Jun. 2009, p.63-81.

CANTINHO, M.J. O conceito de messianismo na obra de Walter Benjamin: da linguagem pura à história universal. In_ : Cadernos Walter Benjamin, vol. 15, jul./dez. 2015, p. 43-61.

FREITAS, J. S. A "miséria do historicismo" e sua desconstrução na filosofia da história de Walter Benjamin”. In__: Cadernos Walter Benjamin, vol. 9, jul./dez. 2012, p. 102- 115.

GAGNEBIN, J. M. Walter Benjamin: os cacos da história. 2 edição. São Paulo: Editora Brasiliense, 1993.

Teologia e messianismo no pensamento de $W$. Benjamin. In_: Estudos Avançados, vol. 13, n.37, São Paulo, set./dez. 1999, p.191-206.

OTTE, G. Linha, choque e mônada. Tempo e espaço na obra tardia de Walter Benjamin. Tese (Doutorado), Universidade Federal de Minas Gerais, pósgraduação em Letras- Literatura Comparada. Belo Horizonte, 1994.

OTTE, G e VOLPE, M.L Um olhar constelar sobre o pensamento de Walter Benjamin. In_: Fragmentos, n.18, jan. /jun. 2000, p.36-47.

PEREIRA, M. A. Repensar o passado - recobrar o futuro: história, memória e 
redenção em Walter Benjamin. In_: Revista História Unisinos, 12 (2), maio/ago. 2008, p.148-156.

SILVA, S. Interrupção e história: Walter Benjamin e Bertolt Brecht. In Revista de Teoria da História, ano 8, vol. 15, n. 1, 2016, p.75-87. 